\title{
The Impacts of Electronic Commerce in the Automobile Industry: An Empirical Study in Western Australia
}

\author{
Peter Marshall, Roger Sor, and Judy McKay \\ School of Management Information Systems \\ Edith Cowan University \\ Perth, Australia
}

\begin{abstract}
While the hype surrounding the promise of electronic commerce seems all pervasive currently, as academics there is a need to conduct empirical studies to establish balanced and credible reviews of the impacts of the Internet and associated technologies on business practice and performance. Also, while the USA is clearly a leader in the uptake of such technologies, it is a moot point as to whether industry trends identified there translate into forecasts for similar industries in different countries and regions. This paper reports findings of a qualitative study of car retailing in Western Australia, aimed at finding out about the impacts of the Internet and electronic commerce from the perspective of senior executives in car retail outlets. Generally speaking, the executives interviewed are experiencing great uncertainty with respect to electronic commerce and its effect on their businesses: they are uncertain about its likely impacts long term (although not much is currently happening), they are uncertain about the ultimate magnitude of electronic commerce in their industry, they are uncertain about the costs and benefits of electronic commerce investments, but they are unwilling not to be involved at all. There appear to be few articulated and carefully thought-out business strategies driving their electronic commerce activities at this stage, nor is there much evidence of internal business processes being reengineered to accommodate the requirements of an electronic commerce presence.
\end{abstract}

\section{Introduction}

Electronic commerce is said to have the potential to alter industry structures and affect the way businesses compete for markets [1]. These effects are already apparent in some industries and specific business organisations in the USA particularly [16], and are just now becoming visible in Australia (see [8]). Arguably therefore, there is a need for Australian-based empirical research particularly at the industry and supply chain level to identify and validate early trends in electronic commerce, and to evaluate and further refine strategies being adopted by business in response to the ecommerce phenomenon. This paper focuses particularly on the anticipated impacts and trends of electronic commerce with respect to the business practices and behaviours, and decision making of car dealers. All the car dealers involved in the study to date are well aware of the Internet, are somewhat aware of the trends in the USA, and the potential of electronic commerce and the Internet to transform their business and to have an immense impact on the way they operate as a business. They 
are all represented in Web sites of various types, or are in advanced stages of preparation of a web presence. But while the promises and the potential are vaguely understood, there appears to be comparatively little direct activity, comparatively little evidence of businesses being engineered to support web-based customer interactions of various types, and a pervasive attitude of "This could suddenly go up like a rocket so we can't ignore it". The paper which follows will describe the research project and explore some of these themes more fully.

\section{The Impacts of Electronic Commerce}

While electronic commerce has been subjected to a wide range of definitions in its comparatively short history, for the purposes of this paper it will be regarded as involving the buying and selling of goods and services over the Internet, and related information provision and gathering [20], [21]. Thus defined, electronic commerce would include business-to-business, and business-to-end consumer transactions and information provision over the Internet.

Many pundits have forecast enormous impacts from electronic commerce in most industry sectors, predicting momentous changes in the world of commerce as we know it today. The interconnectivity and pervasiveness of the Internet do open new possibilities for the organisation of work, for the management of the supply chain and formation of dynamic trading networks [18], and for entrepreneurs to meet the needs and demands of ever-better informed consumers [4]. These trends clearly impact the retail sector. While some authors go as far as to predict the demise of bricks and mortar, 'High Street' shopping [3], others forecast a rapid growth in Internet shopping but still anticipate healthy activity in High Street shops, arguing that such shopping in fact meets important social, cultural and psychological needs [9],[16]. The extent of the impacts of electronic commerce in retailing remains somewhat difficult to predict with accuracy: conservative estimates suggest that Internet shopping may ultimately account for $10-15 \%$ of the retail sector [15].

Arguably as a particular categories' on-line sales surpass $10 \%$ of total sales, retailers will be forced to change their business models and practices, and take account of these trends towards electronic commerce [16], [17]. Of particular interest for this paper are trends in car sales, with obvious interest placed in the changes to existing High St car yard business practices and models.

\section{Impacts of Electronic Commerce on the Car Retail Industry}

As there is to date no known published information on the effects of electronic commerce on car retailing in Australia, discussion at this stage must be limited to a consideration of trends and forecasts in the USA. Sales of cars in the USA, both new and used, have not escaped the impacts of electronic commerce. By 1998, for example, it was argued that more than $10 \%$ of sales of new and used cars were influenced by the Internet. Thus, 2 million purchases of new cars and 4.2 million purchases of used cars were reliant to some extent on electronic commerce [14]. The exact role of the Internet perhaps need to be clarified however. In some retail 
categories, the Internet plays an important role in most, if not all, phases of the business transaction. Thus, information provision, purchase request, financial transaction, and possibly delivery of the good are all facilitated by the Internet, for example. Typically, this is not the case in the car industry, nor is it predicted to be [13].

Currently, some car purchasers are using the Internet to research vehicle types and features, and to identify and locate vehicles potentially of interest. Having made a decision about the make and model of car(s) in which they are interested, typically these consumers then go about transacting the rest of their car purchase in the more traditional manner. Of the 2.8 million Internet-influenced sales of new cars in 1998, approximately 2 million of these used the Internet for exactly this purpose [11]. Most of the remaining Internet-influenced purchasers used the Internet to locate a dealer stocking the particular type of vehicle they are interested in. At the moment, almost no complete sales are made over the Internet, nor are additional arrangements such as finance, insurance and additional warranty options generally made over the Internet. Both these areas however, are anticipated to become available by 2000 , and to grow substantially by 2003 [12].

Thus, in America at the moment, comparatively few new car sales are made directly by the car manufacturer to the end consumer. Occupying a far more important role in both the new and used car marketplace are various intermediaries, who each list many dealers and offer the consumer the ability to search on various parameters, such as car type, price range, geographic location, and so on, in order to locate a smaller cohort of potentially suitable cars within reach of their homes or offices to facilitate further personal enquiry. In total, it is estimated that more than 4 million used cars will be listed on these on-line buying services in 1999, some $10 \%$ of the used cars that will be purchased this year. These intermediaries offer car dealers a substantial number of referrals each month: the larger and more successful sites may be referring more than 100,000 clients to dealers each month [11].

It could be argued that the US experience with electronic commerce seems several years in advance of Australia with respect to its acceptance and adoption of on-line retailing, and given reasonable similarities in business trends and culture between the USA and Australia, it could provide a useful model for local businesses to consider in order that they can prepare for the future. However, it could also be asserted that there are important differences in the Australian business environment, thus rendering the data and trends from the USA unreliable as predictors of trends in Australia.

\section{The Research Project}

The research project was designed to consist of a series of qualitative, semistructured, research interviews with senior executives (managers and/or owners) of a variety of car dealerships in the capital city of Western Australia. Each interview was based on a set of interview questions, based on the trends in electronic commerce in the retailing sector, and specifically, in the car industry, and also on the authors' knowledge of electronic commerce trends in Australia. Some flexibility in approach was adopted to accommodate and be responsive to the varied responses received from interviewees. The interviews conducted lasted between 1.5 and 3 hours, and were crafted to encourage the senior executives interviewed to describe their 
understandings of electronic commerce, and to articulate their beliefs about the impacts of electronic commerce and the Internet on their business activities and practices in the future. The interest of the researchers was thus to arrive at an understanding of the impacts of electronic commerce from the CEOs'/owners' perspectives and to reveal their feelings and beliefs about electronic commerce, indicating that the qualitative research interview was an appropriate vehicle for the conduct of this research [6].

Each of the interviews was transcribed and subject to qualitative content analysis. The specific approach used is detailed elsewhere (see [10]), but involved categorisation of responses into certain themes, some of which were inherent in the interview questions, and some of which emerged through the interviewees' responses to questions posed. Some nine interviews have been conducted to date. In citing from these transcribed interviews, the convention CY1-CY9 has been adopted (Car Yards $1-9$ ) in order to conceal the identity of any specific dealer.

\section{Findings of the Research}

A number of themes or issues have emerged as a result of the interviews conducted to date. Each of these will be briefly described and discussed below. However, generally speaking, it seems fair to say that the Internet is causing both interest and uncertainty amongst the car dealers. Already, there are some impacts of electronic commerce being felt, such as the reengineering of the industry supply chain (discussed below). However, few of the car dealers feel certain as to how large the impacts of electronic commerce might ultimately be, and few of the businesses seem to be adopting quite deliberate and explicit strategies with respect to electronic commerce. There was generally little evidence of internal changes being made in response to opportunities offered by electronic commerce initiatives.

\subsection{Impacts of Electronic Commerce on the Car Industry Supply Chain}

The car industry has traditionally relied on a fairly uncomplicated supply chain. Car manufacturers (typically fairly large, prominent organisations) draw raw materials and other component parts from a number of suppliers. Finished new cars are then distributed to a network of car dealers, for on-selling to the end consumer. End consumers may sell used cars back to dealers (perhaps as a trade-in on another car, although not necessarily), or alternatively, may privately organise sales of used cars direct to other end consumers. Figure 1 illustrates these relationships.

Proponents of electronic commerce might argue that, amongst other things, the advent of the Internet in the car industry supply chain may result in disintermediation [2], [7]. Long term this may occur, with new car buyers specifying requirements and purchasing direct from manufacturers. However, current industry activity with respect to electronic commerce does not indicate that this is occurring to any great extent as yet. Rather, Figure 2 portrays the changes occurring in the industry. 


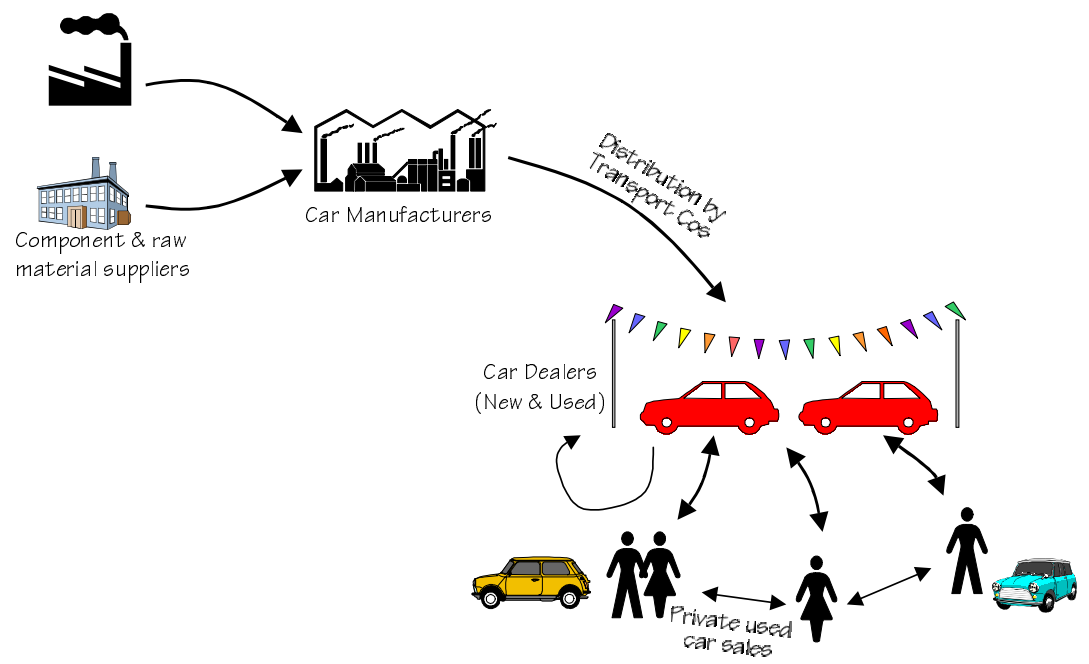

Fig. 1. Traditional Car Industry Supply Chain

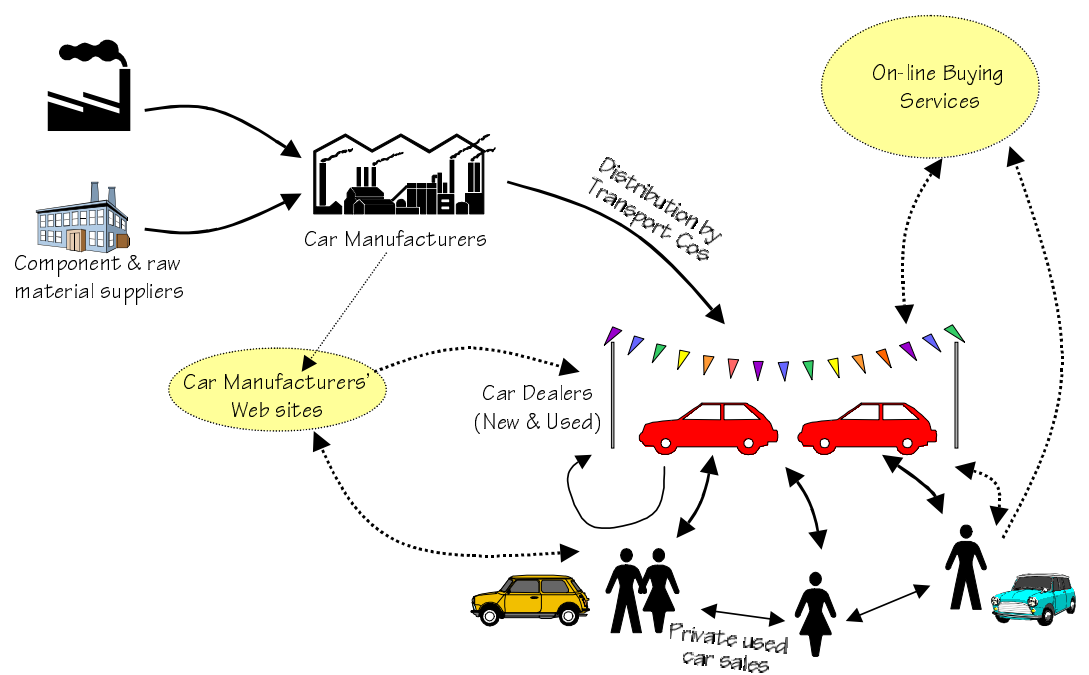

Fig. 2. The Effects of Electronic Commerce in the Car Industry

Already in the Australian car retailing industry, electronic commerce has seen the advent of on-line listing and buying services, acting as a conduit of information, referrals and expressions of interest between end consumers and new and used car dealers. Thus dealers register with these on-line buying services, regularly providing updates on the range and features of vehicles they have available for sale. In exchange, the on-line service providers facilitate placing interested customers in touch with the relevant dealer. Some of the dealers interviewed believed it was necessary to be represented on at least one of these electronic marketplaces. 
CY4: "I mean the job of a dealership, I believe is to get customers into the door, once you've got them in the door, hopefully, sales...it [on-line buying services] is very useful, so soon some of us, we will lose some deals" (if they did not become part of the on-line buying service).

Car manufacturers are also developing a presence on the Web, whereby interested end users are directed towards a preferred dealer located close-by [19]. While the CEOs interviewed did not envisage the disappearance of the car dealerships as consumers purchased direct from manufacturers, they did concede that they could not be complacent about their role given the influence of the Internet and changes already occurring in the industry supply chain. Of interest was the fact that some of the car dealers felt pressured by the car manufacturers to establish a web site with links to other sites.

CY3: "Our name's already on all the manufacturer's sites. And our address and email address... and when we finish building our web site, you'll click down to us from the manufacturer...Further to that, there's pressure on us from the manufacturer to have a web site...(And then in response to a question whether the pressure came from a particular manufacturer) Yes. From all of them. From the manufacturers."

CY5: "We're being pushed by the manufacturers to be in there."

\subsection{Awareness and Attitudes to Electronic Commerce}

The situation regarding the Internet and car retailing in Australia seemed to be one of great uncertainty and some anxiety on the part of the car dealerships. There is some awareness of the U.S. scene and the increasing importance of the Internet in retailing in general and car retailing in particular in that country.

CY4: "But, eh, there is obviously a lot of information in terms of how much business has actually been done on the net, not people just looking, and making predictions that by 2000, America was about 35\% signing contracts without actually being done face to face contact."

However, typically, senior executives are informed through their reading of the popular press and through television reports, but none of those interviewed to date have undertaken serious research into electronic commerce. Very few persons in the car retailing industry in Australia are willing to forecast the future role and importance of the Internet in car retailing in Australia, although they generally suspect that it will be significant.

CY8: "We really are nowhere yet with the Internet other than we know it's going to work and it's in the infancy stages. It's already showing positive signs, and we will move towards it pretty quickly. Should be interesting to see in 12 months time reflect and see." 
However most of the larger car dealerships, particularly those with annual revenues of greater than \$10 million per year, have an Internet presence now or plan to have one in the near future. The smaller players in the industry are also either established on the Web, or are planning to become so in the foreseeable future. The web presence is usually accomplished through the electronic malls or marketplaces which were briefly outlined previously when discussing changes to the car retail industry supply chain.

Overall there is a moderate amount of skepticism about the Internet and its importance in new and used car retailing in Western Australia. Little has happened yet, and there is some feeling that despite some journalistic stories and government reports heralding great changes, little will happen, at least in the short term future.

CY4: "What is happening is that we are getting some initial interest-only enquiries over the Internet...but so far is so small relative to the opening of the site."

But there is great uncertainty also. Interviewees generally acknowledged that electronic commerce and the Internet could become enormously important to their businesses, although they were uncertain as to exactly what impacts it might have, how dramatic these impacts would be, and on how these changes might be realised in their specific businesses. Despite the skepticism, none of the interviewees were willing to completely ignore electronic commerce at the moment: there was always the concern that it might suddenly become very significant, and they did not want to risk being 'left behind'.

\section{CY7: "No, no we suspect that we'd better be there."}

CY5: "So the whole email thing and Internet is a wild card. This one's from our point of view, but we don't know where the hell it's going."

CY1: "Obviously our business has to be competitive, and we have to keep up with the latest marketing trends...I am only at this stage paying a token gesture I think towards the Internet, we haven't really done it properly."

Also, it must be said that many of the dealers wanted to use the Internet to arouse interest, but actually wanted then to handle the transaction face-to-face.

CY2: "What is happening is that people are searching for products from the Internet...I don't know whether, or how many people would buy from the Internet, if you're talking about a commodity like a motor car, I still believe people still want to touch it."

CY9: "I don't think anyone would spend their money firstly without being able to touch it, see it, and I don't think we want that way either, because that person is important..."

CY4: "The point I was getting to, I don't think anybody would want to buy used cars without touching it and seeing it." 
CY8: "I'm certainly not trying to encourage people to buy a motor car on the Internet. I'm trying to initialise enquiries as a result of finding a car on the Internet...The Internet is very useful to provide interesting useful information...I require enquiries from the Internet, I want then to get face-to-face."

It could hardly be asserted that the car dealerships had articulated a clear vision of electronic commerce for their organisation, which they were now pursuing through appropriate strategies. Rather, the articulated strategy was 'We have to be on the Web, because otherwise we might miss out'.

CY3: "Jeez, we've got to have a bloody web site now before everybody else out there does it."

CY4: "I am computer illiterate, emm...effectively the only decision that I had was to keep it simple. By me bringing the vehicle into stock, my car system automatically goes to the system [the on-line buying service] and then links it straight to the Internet."

CY8: "It has been said time enough that the worst thing you could do is wait until the Internet gets big...it would be so much behind... We might as well get in at an early stage."

In terms of the electronic commerce maturity model developed by the Nolan Norton Institute for KPMG, these car dealerships were at the Experimentation Stage or Stage 1 in their adoption and use of electronic commerce (see Figure 3 below) [5]. If they are to migrate to more mature stages, then according to this model, considerable changes will be required. To achieve Stage 2, they will need to develop policies and have more of a deliberate business focus to their web-based activities. Comparatively few of the dealers interviewed seemed to believe that the car industry would ever achieve Stage 3, where transactions are completed on-line, although some thought that the Internet would over time become more and more integrated with their normal business operations.

\subsection{Effect on Business}

All of those interviewed said that there was little effect of the Internet on sales to date and they felt that this would remain the case for the short-term future.

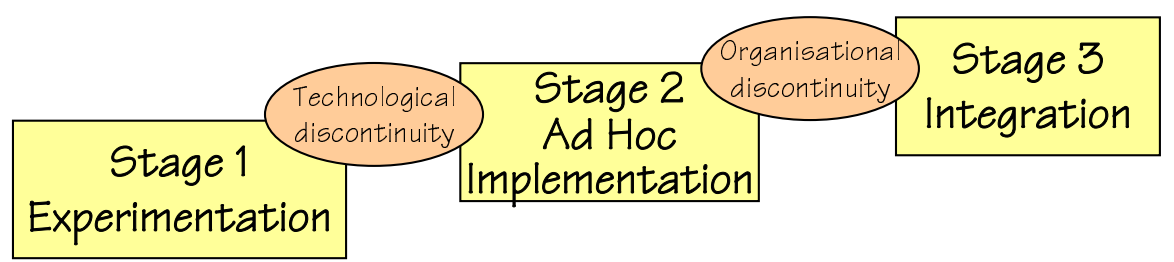

Fig. 3. Electronic Commerce Maturity Model [5:11] 
CY4: "New car enquiries...zero June, zero July, zero August, zero September, October to November 7 [enquiries], December zero, January 1 [enquiry]...So its zero, zero, zero..."

The Internet, they felt, would not be a medium over which actual sales would take place, but might be a medium which would influence buyers in terms of which car dealerships that they approached. The actual selling of cars, or at least the end subprocess of selling cars, would thus remain in the hands of the car dealerships' sales persons, but the flow of customers to car dealerships might well in the future be affected by the Internet. Their sentiments very much echoed the trends that were discussed earlier in this paper with respect to the impact of electronic commerce on the American car industry.

CY1: (reporting on a story he had heard about a customer) "...I would never buy a car that way [over the Internet]...I want to smell it!...Computers can not open and shut the doors, I can't smell the trunk, and I can't smell the car..(Responding to a question about whether salespeople would disappear because of the Internet) "I don't see that happening for a long, long time in Australia." (Responding to whether customers decision making would be informed by the Internet) "Yeh, yeh, sure, sure I think in time it will be...I think it will be."

However, a particular point which moderates the comments above needs to made at this juncture. None of the car yards involved in the interviews to date appeared to have any mechanism to detect whether a customer walking in did so as a result of newspaper advertising, Internet on-line buying services, referral by a satisfied customer, quite serendipitously, and the like. Thus, it appeared that none of these businesses had made any effort to find out whether their customers had conducted an initial search over the Web, and whose approach to the company was thus motivated by information obtained over the Internet.

\subsection{Impact on Business Processes}

Despite each of the car dealerships having web sites, the business processes of each dealership were not well integrated with the web site. It was not always clear in each dealership just how Internet based enquiries were to be dealt with nor exactly who would deal with them. All the car yards had well-established mechanisms for handling new 'walk/phone-in' customer enquiries, but they were somewhat concerned about how equitably, efficiently and effectively to deal with e-mails generated from on-line buying services. It is one thing to enable e-mail links to the organization: it is quite another to design internal business processes to ensure the e-mail is responded to appropriately. Neither did it appear the dealerships were geared up to keep good commercial records of web activity, nor ready to measure important statistics such as look-to-buy ratios. Generally speaking, they had not carefully thought out appropriate business processes to handle Internet enquiries. 
CY1: "Can I tell you something that would probably surprise you? I don't know."

CY4: "You've got a job to link the Internet activities to your sales people, something that changes the business a bit, with a lot of stuff made through the Internet...How do you monitor your salespeople, and then reward it?"

\subsection{Drivers and Inhibitors of Electronic Commerce}

By far the major driver of developing a presence of some sort on the Internet was the fear of being left behind by competitors when (and if) 'something happened'. These business people seemed very concerned not to miss out on a business opportunity should one present itself!

CY8: "It's paramount. Anyone who doesn't get into it [electronic commerce] is bloody mad!"

The presence of competitor car dealerships on the Internet is not the only factor driving car dealerships to consider a web presence in some form. The dealerships that sell new as well as used cars are under pressure from the automobile manufacturers to have a web-site. This leads to listings of car dealerships on manufacturer's sites. These listings often include some web pages with advertisements for used cars from the dealership. However these alternative web sites are not always linked to the electronic marketplace presence of the dealer, thus illustrating that it is early days yet in the utilisation of the Internet and a well planned coordinated approach to the web has not occurred yet.

By contrast, others expressed suspicion of the concept of on-line buying and Internet-influenced sales, particularly given the fact that the electronic malls or marketplaces that were being establishing were such that each dealer was there as one among a crowd, his/her cars part of a larger pool to be searched by customers. The car dealers interviewed were clearly accustomed to regarding fellow dealers as competitors, and many seemed decidedly uncomfortable at participating in the same on-line buying service as their major rivals. However, they also had enough business acumen to realise that from a customer's perspective, such on-line buying services facilitating cross-dealer searches were an attractive proposition.

CY1: "So, so, I am anti-the Internet because of its over-information in this particular instance of the car business...I don't want anything to do with other Ford dealers or Mitsubishi dealers...I mean...they are my enemy!"

CY9: "I have heard that in the USA, you can find the price that new cars are sold to dealers by the manufacturers on the Internet...I think that's obscene!" 
The other major inhibitor to electronic commerce seemed to stem from the difficulty that the senior executives interviewed seemed to be experiencing in evaluating their investment in electronic commerce. Most of these executives were looking for some sort of cost / benefit with respect to their Web and associated investments. However, at this stage, they generally felt that there were few tangible benefits to speak of other than comparatively low-cost advertising, and typically, they struggled to appreciate the 'worth' of so-called intangible benefits. This issue certainly contributed to a feeling of uncertainty about the value and impact of the Internet. Nevertheless, none of the dealers interviewed was prepared not to remain totally uninvolved until someone else (one of their competitors!) demonstrated the value of electronic commerce investments by deriving considerable business benefits from the Internet.

CY8: "The cost of advertising is bloody expensive. And at the moment, the majority of used car advertising is in real life...predominantly newspaper... One of the big advantages with the Internet for you is the low cost of actually advertising."

\subsection{Web Site Design and Management}

Most of the dealers had an ad hoc approach to their web sites. Many talked about feeling pressurised by IT consultants into developing web sites without too much consideration of a planned business initiative to move into electronic commerce. The care and maintenance of the web site was not, in general, professionally planned and managed. In one case, for example, the finance manager had somewhat reluctantly inherited the task of maintaining the web site, without having any apparent great interest or expertise in the area.

CY8: "We've been interviewed by enough web site manufacturers to sink a ship. It's a bit like "You need to get involved in our web site." But once you see the sites, you know...there's room there for someone to say "Give us $\$ 700$ and we'll come back next week with your web site." Yeah, Ok. There are con-merchants, yes. There are con-merchants."

It was not always clear what policies and standards had been set for presenting individual cars and the dealership in general on the web. Sometimes a number of cars in the dealership stocks did not appear on the web site. Of those that did appear some had photographs of the car concerned and others did not. There appeared neither rhyme nor reason to these and other aspects of the web advertisements. There seemed to be a much more professional attitude and practice in dealing with conventional media such as newspapers and radio.

\section{Conclusion}

The car industry in Western Australia thus remains only superficially affected by the technology and presence of the Internet. Each of the major car dealerships 
interviewed for this study have web sites, albeit on electronic malls which seem very much like the forerunners of the powerful Internet buying services of the USA. Some, again like their US counterparts, have web sites connected to manufacturers' sites. However, their Internet site, detached from the energetic, everyday business of selling cars and making money, is the beginning and end of Internet-based commerce for the car dealerships. Cars are not selling over the Internet, and apparently in the eyes of the car dealers, people's buying behaviour is not being influenced by the Internet.

Thus, after a small burst of activity in establishing a web site so as to be prepared for electronic commerce, all has gone quiet. CEOs and senior managers are back to the main job of selling cars as usual. They are, however, quietly anxious about what might happen next week, in the next year or so, or next decade on the Internet in their industry.

What is needed is some reflective thinking and some action planning with respect to electronic commerce. If the US experience is a guide as to what will happen in Australia, then it would seem timely to plan and enact the reengineering of business processes such that the Internet and associated internal systems are well integrated with the selling processes integral to the business. Included in this will be careful monitoring of web site activity and the establishment of procedures to measure Internet-based referrals and Internet-influenced sales. For example, dealers may need to become familiar with electronic commerce metrics such as look-to-buy ratios, and so on. The new position of the car dealerships to the Internet buying service companies must be thought through as should the other new relationships in the industry supply chain. A time of moderate to significant change is approaching and some strategy formulation together with some IT and electronic commerce supporting strategy formulation would be helpful in charting an appropriate path to the future.

\section{References}

1. Applegate, L.M., Holsapple, C.W., Kalakota, R., Radermacher, F., and Whinston, A.B. (1996) Electronic commerce: building blocks of new business opportunity. Journal of Organizational Computing and Electronic Commerce, 6(1): 1-10.

2. Choi, S.Y., Stahl, D. and Whinston, A.B. (1998) Intermediation, contracts and micropayments in electronic commerce. Electronic Markets, 8(1): 20-22.

3. Davidow, W.H. and Malone, M.S. (1992) The Virtual Corporation. HarperCollins, NewYork.

4. Hoffman, D., Novak, T.P., and Chatterjee, P. (1999) Commercial scenarios for the web: opportunities and challenges. Journal of Computer Mediated Communications, 1(3)

URL http://www.ascusc.org/jcmc/voll/issue3/hoffman.htm

5. KPMG (1999) Electronic Commerce: The Future is Here! URL www.kpmg.com.au

6. Kvale, S. (1996) InterViews: an Introduction to Qualitative Research Interviewing. Sage, Thousand Oaks.

7. Laudon, K.C. and Laudon, J.P. (1999) Management Information Systems: Organization and technology in the Networked Enterprise. $6^{\text {th }}$ ed. Prentice Hall, New Jersey.

8. Lawrence, E., Corbitt, B., Tidwell, A., Fisher, J. and Lawrence, J.R. (1998) Internet Commerce: Digital Models for Business. Wiley, Bridbane.

9. Maruca, R.F. (1999) Retailing: confronting the challenges that face bricks-and-mortar stores. Harvard Business Review, 77(4): 159-168. 
10.McKay, J. (1999) The Application of soft Management Science / Operational Research to Information requirements Analysis: a Study using Cognitive Mapping and the SODA Methodology. Unpublished $\mathrm{PhD}$ thesis (under preparation), Edith Cowan University.

11.McQuivey, J.L. (1999) Used Car Buying Builds Steam, The Forrester Brief, March 1999, URL http://www.Forrester.com

12.McQuivey, J.L., Delhagen, K. and Ardito, C. (1999) New-Car Buying Races On-line, The Forrester Report, 1(10), January 1999, URL http://www.Forrester.com

13.McQuivey, J.L., Delhagen, K., Levin, K. and LaTour Kadison, M. (1998) Retail's Growth Spiral, The Forrester Report, 1(8), November 1998, URL http://www.Forrester.com

14.Ohlson, K. $40 \%$ of new-car shoppers use net for research. Computerworld Online News, $08 / 23 / 99$.

15.Reynolds, J. (1987) The Internet as a strategic resource: evidence from the European retail sector. In L. Willcocks et al. (eds.) Managing IT as a Strategic Resource. McGraw Hill, London.

16.Robinson, K.G. (1999) E-commerce: sales and demand suppression. Telecommunications Reports Journal, 3(1): 17-20.

17.Salnoske, K. (1999) E-commerce in 1999: what to look for. Telecommunications Reports Journal, 3(1): 45-49.

18.Scharl, A. and Brandtweiner, R. (1998) A conceptual research framework for analyzing the evolution of electronic markets. Electronic Markets, 8(2): 39-42.

19.Stair, R.M. and Reynolds, G.W. (1999) Principles of Information Systems, $4^{\text {th }}$ ed. Course Technology, Cambridge, MA.

20.Von Versen, K. (1999) The three commercial functions of the internet. In B. Buchet et al (eds.) EC in the Insurance Industry, Electronic Markets, 8(4):02/99.

21. Whiteley, D. (1999) Internet commerce - hot cakes and dead ducks. In F. Sudweeks and C.T. Romm (eds.) Doing Business on the Internet: Opportunities and Pitfalls. Springer, London. 